\title{
Affective Pedagogical Agent in E-Learning Environment: A Reflective Analysis
}

\author{
Atasi Mohanty \\ Centre for Educational Technology, Indian Institute of Technology, Kharagpur, India \\ Email: atasim@cet.iitkgp.ernet.in
}

Received 15 February 2016; accepted 10 April 2016; published 13 April 2016

Copyright (C) 2016 by authors and Scientific Research Publishing Inc.

This work is licensed under the Creative Commons Attribution International License (CC BY). http://creativecommons.org/licenses/by/4.0/

\begin{abstract}
In educational research the relationship between affect/emotion and performance on cognitive tasks is well documented in both the neuroscience and psychology literatures. Researchers have claimed that emotions play a vital role in perception, learning, decision making, rational thinking and other cognitive functions. At the same time some others have added that both the positive and negative affective states are equally important in the learning process. In the real-life physical learning environment students' affective feedback is a major cue that human tutors use to constantly adapt their teaching strategies, so that learning would be most effective and efficient for each individual learner. Thus, in e-learning environment it's a research issue to think about how to design an artificial affective tutor or pedagogical agent, who can respond to students' emotion and accordingly guide and motivate them for better learning. However, for post-secondary learners it may be relevant, but for secondary level Indian students can it be feasible and cost-effective ICT learning tools. This raises many more questions about content, pedagogy, software designing and implementation of affective pedagogical agents as ICT learning tools in Indian school education system.
\end{abstract}

\section{Keywords}

Affective Tutor, Pedagogical Agent, Intelligent Tutoring System, Cognitive Computing, ICT Learning Tools

\section{Introduction}

In educational research the relationships between affect/volition and performance on cognitive tasks is well documented in both the neuroscience and psychology literatures. Researchers have claimed that emotions play a vital role in perception, learning, rational decision making and various other cognitive functions (Picard, 1997); emotions significantly influence cognitive tasks like planning, decision-making, adaptation to learning and new 
environments as well (Lisetti, 1999). Thus, performance on cognitive tasks, such as "learning” cannot be considered as distinct from affective state of the learner, as the latter unquestionably influences the former? (Bechara, Damasio, \& Damasio, 2003). For example positive affect facilitates cognitive tasks like creative problem solving and cognitive organization and enhances the intrinsic motivation for accomplishing tasks (Isen, 2000; Isen, \& Reeve, 2005), which confirms that positive affect/emotion can boost the performance in cognitive tasks. However, some other researchers have added that both positive and negative affective states and important in the learning process (Kort, Riley, \& Picard, 2001). Here we can refer to the "student affect \& learning" model of (Kort et al., 2001) (Figure 1).

\section{According to This Model}

Students typically orbit the quadrants in an anti-clockwise direction as they attempt to solve a problem. Both the positive and negative emotions are a natural part of students' normal learning cycles. Tutors can help the students' learning process through an awareness of their affective states. If a students' learning process intrinsically involves a journey through distinct emotional states, then identifying these emotional states would help an intelligent tutor to speed up this learning process on its positive way (Kort et al., 2001). Hence, an affect-sensitive tutoring system is very important to deal with the students' affective state in learning environment and especially in e-learning context.

\section{Affective Tutor}

In real life physical learning environment students' affective feedback is a major that the human tutors use to constantly adopt their teaching strategies (Lepper, Aspinwall, Mumme, \& Chabay, 1990; Fox, 1991; Merrill, Reiser, Ranney, \& Trafton, 1992). Moreover, human tutors use the affective information they receive from learners to individualize the tutoring session, so that the learning is as effective and efficient as possible for each individual student/learner (Kort et al., 2001). The affective feedback from students that human tutors adapt can take many forms such as facial expressions, gestures and vocal inflections (Picard, 1998), mostly either non-verbal or paralinguistic (affective communication) in nature. Due to this non-verbal, voice modulation and spontaneous/involuntary responses, the human tutors constantly receive a significant amount of affective feedback during tutoring session, which tells the moods and emotions of the learner, whether he/she is happy, confused, frustrated, surprised, bored or content with the learning materials being presented to him. Mostly human tutors use this information to adapt their teaching to match the affective state of the learner (Sarrafzadeh, Fan, Dadgostar, Alexander, \& Messom, 2004). Thus, it implies that capable intelligent tutors who could adapt to students' emotions could also significantly enhance their learning and performance. But, unfortunately very little research has been done to address the details of how human tutors adapt to particular affective signals in particular teaching scenarios (Alexander, 2007). Hence it's research issue to think about how to design an artificial affective tutor/pedagogical agent, who could respond to students' emotion and accordingly guide and motivate them for better learning.

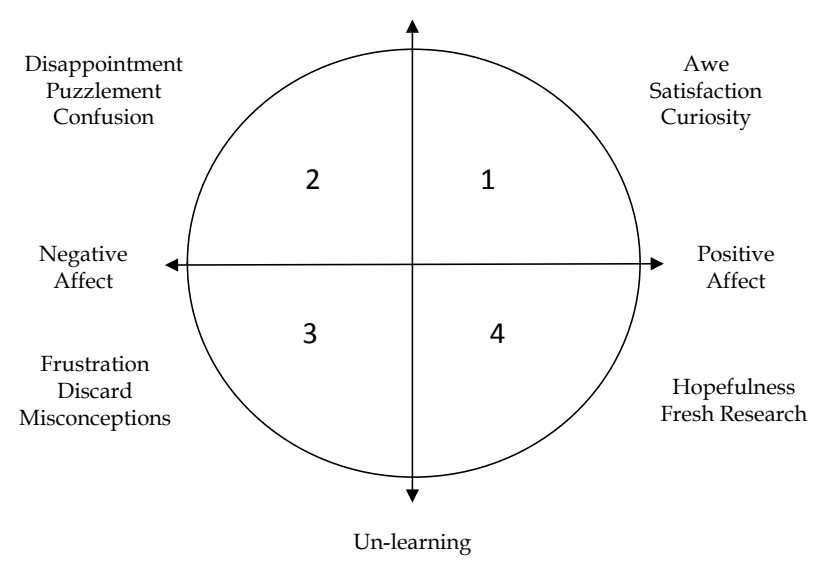

Figure 1. Four quadrant model of student-affect \& learning (Kort et al., 2001) constructive learning. 


\section{Pedagogical Agents}

According to research literature pedagogical agents are anthropomorphous virtual characters employed in online learning environments to serve various instructional goals. Very often they act as instructors or motivators and can interact with learners through gestures, natural language or facial expressions. Mostly the pedagogical agents are integrated in e-learning environments as they are assumed to be capable of providing cognitive support to the learner (Baylor, 1999) and social enrichment to the learning experience (Gulz, 2005). Thus, agents can provide human-like assistance (e.g. answering the questions), as well as reduce learner anxiety and frustration (by appearing as friendly tutor). Broadly two sub-categories of agents are found in research literature i.e. conversational and Teachable agents. Conversational agents are able to hold conversations with e-learners and teachable agents are characters/features that the students teach to complete various activities (e.g. solving puzzles). Thus, the history of pedagogical agents in e-learning environment can be traced back to 1970s, with the development of “Intelligent Tutoring Systems” (ITS) (Veletsianos \& Russell, 2013).

\section{Qualities of Pedagogical Agents}

An ITS exhibits characteristic features similar to a human tutor, such as being able to answer student questions, detect misconceptions and provide accurate feedback. Recently, the agents are also seen as having social (andrelational) artifacts, besides cognitive assistance. Thus, in an e-learning environments the pedagogical agents play multiple roles such as tutors, coaches, and actors (Payr, 2003), experts, motivators and mentors (Baylor \& Kim, 2005); learning companions (Kim, Baylor, \& Shen, 2007); change agents (Kim \& Baylor, 2008); and lifelong learning partners (Chou, Chan, \& Lin, 2003). Often, learners may stereotype agents according to their appearance (Veletsianos, 2010), and appealing visual appearance enable agents to function as active social role models for e-learners (Kim \& Baylor, 2006; Rosenberg-Kima, Baylor, Plant, \& Doerr, 2008). Thus, their defining roles are:

1) Adapt-A pedagogical agent evaluates the learner's understanding throughout the interaction, just as a human teacher would, and adapts the lesson plan accordingly. Agents will not move on to more sophisticated concepts until it is clear that the learner has a good understanding of the basics; if learners continue to have difficulty, the agent can provide additional instruction.

2) Motivate-Pedagogical agents can prompt students to interact by asking questions, offering encouragement and giving feedback. They present relevant information offer memorable examples, interpret student responses and even tell a clever joke or two.

3) Engage-Pedagogical Agents have colourful personalities, interesting life histories, and specific areas of expertise. They can be designed to be the coolest teachers in school.

4) Evolve-Pedagogical agents can be revised and updated as frequently as necessary to keep learners current in a rapidly accelerating culture. They can search out the best or most current content available on the web to enrich the lessons that someone else has previously designed.

\section{Affective Computing}

The interplay between emotions and computer, widely known as “affective computing” is generally traced back to Rolalind Picard's (1997) book on this topic, where she defines this as "computing that relates to, arises from, or deliberately influences emotions”, plays an important role in the "Human Computer Interaction” (HCI), especially in personalized e-learning context (D’Mello, Picard, \& Graesser, 2007; Prendinger, Mori, \& Ishikuza, 2005). The latest scientific findings indicate that emotions play a vital role in decision-making, perception, learning, rational thinking and more. In particular, the role emotions play in learning process is more and more acknowledged both in educational and cognitive science research literature (Gardner, 1999; Kinard, 2001; Schutz \& Pekrun, 2007), In academic and educational contexts, emotions were found to be significantly related to student motivation, learning strategies, cognitive resources and achievement (Pekrun, Goetz, Titz, \& Perry, 2002), affective in learning facilitates the development of persistence and interest in a topic (Barrett \& Salovey, 2002), emotions can influence learning through information processing activity and organization of recall (Pekrun et al., 2002). Studies in cognitive science research also pointed out that positive and negative emotion can trigger different neural activity patterns and thinking styles (Damasio et al., 2000; Isen, 1999; Lane et al., 1997). The presence of a positive emotional state can foster a thinking style characterized by higher creativity and 
flexibility in problem solving by more articulated information processing and higher efficacy in decision-making (Isen, 1999; Picard et al., 2004). On the contrary, negative emotions, such as fear, sadness and anger can influence the blood in flow to different brain areas, making learning more difficult (Damasio et al., 2000; Lane et al., 1997).

Thus, affective computing within the Human-Computer-Interaction (HCI) framework can be a valid tool to develop a well integrated e-learning environment to deal with emotional aspects in learning process (Picard et al., 2004). Primarily, there are three trends in affective computing which carry a potential for improving the e-learning experiences. For example-

1) The use of "Animated Pedagogical Agents" with affective features as virtual tutors;

2) The possibility of automatic recognition of (and adaptation to ) learner's emotional and motivational state;

3) The use of 3D simulation and immersive environments for web-based training of emotional competence. Pedagogical agents should ensure adequate social presence in individual e-learning setting, playing the role of a tutor, thus need to be designed according to consistent pedagogical models and to be appropriately endowed with communicative and emotional competence.

\subsection{Affective Tutor/Pedagogical Agent}

The affective pedagogical agent should be endowed with both the cognitive and affective architecture. In the e-learning environment the affective tutor is not only expected to create a friendly and engaging learning environment but also to assist the learner increase his/her meta-cognitive awareness and improve his emotion regulation abilities in coping with difficulties encountered during learning. Secondly the affective tutoring system should be embedded with the ability to infer user's emotions, and react to them by adapting the learning path and experience (Mantovani et al., 2010). Another emerging trend in affective tutoring is aimed at focusing on soft-skill training in e-learning, with special emphasis on experiential learning, e.g. socio-emotional and communicative skills.

Thus, the "Affective Tutoring Systems" (ATS) are ITSs (Intelligent Tutoring Systems) that are capable of adapting to the affective state of students in the same ways that effective human tutors do (Alexander, Sarrafzadah, \& Hill, 2006; de Vicente, 2003). Although the affective computing has started way back in 1997 (Picard R.) the Affective Tutoring System came into lime-light only a decade ago. With certain characteristics the ATS was developed.

1) Recognizing emotion-Recognizing user motion is absolutely fundamental to any attempt of developing and implementing an ATS. There are different areas of emotion detection which could be captured through affective signals, such as

a) Vocal inflections, prosodic qualities of speech,

b) Motor and physiological uses (Mota \& Picard, 2003; Prendinger \& Ishizuka, 2007)

c) Facial expressions

2) The ATS should be able to show emotions too. Thus, in ATS emotions are generally shown through lifelike tutoring characters, also known as animated pedagogical agents (Prendinger \& Ishizuka, 2004), i.e. agents that take the role of teacher-AutoTutor; the role of a learning companion or the agents that simply act as a guide. The primary benefit of animated characters is that they carry a "personal effect" which increases learner motivation and engagement.

3) The third attribute of ATS relate to computer's ability to have emotion and its ability to act in an emotionally intelligent manner, i.e. to be "skilled at understanding and expressing its own emotions, recognizing emotions in others, regulating effect, and using moods and emotions to motivate adaptive behaviours". (Picard, 1997). Thus, it's absolutely essential for an effective tutor to be believable and positively engaging to students.

The affective Tutoring System (ATS) has the theoretical foundations well connected to various disciplines e.g. Education, psychology, computer science and Instructional design, as well as theories/paradigms like-computers as social Actors paradigm (CASA, Reeves \& Nass, 1996) "Socio-cognitive theory” of Bandura (1986) "Cognitive Load Theory” of Sweller (CLT, 1994, 2004) and working memory model of Baddeley (1992).

\subsection{Research on Pedagogical Agents: Outcomes and Challenges}

E-learning researchers claimed that pedagogical agents could afford "increased motivation increased sense of 
ease and comfort in a learning environment, stimulation of essential learning behaviours, increased smoothness of information and communication processes fulfillment of need for personal relationships in learning and gains in terms of memory, understanding, and problem solving" (Gulz, 2004), but the evidences are often mixed and contradictory. Some have also claimed that pedagogical agents are capable of aiding learning, delivering content, and supporting both cognitive processing and meta-cognitive skills (Clarebout \& Elen, 2007) through flexibility, support and guidance. Even, pedagogical agents are able to monitor and adapt to students' learning styles backgrounds, and behaviors in order to individualize instruction (Sklar \& Richards, 2010; Woo, 2008). A very popular PA “Auto Tutor" uses dialogue feedback, corrective statements, hints, fill-in-the blanks questions \& requests for more information from the user (Graesser et al., 2008). However majority of research have found that these agents have technological constraints and need controlled environment for experimental research. Researchers have claimed that PAs provide realistic stimulations by replicating human behavior (Sklar \& Richards, 2010) like demonstrative procedural tasks, using gesture and gaze as instrumental strategies, enact think a loud to stimulate reasoning, meta-cognition and model appropriate social behaviour as human tutor. Thus, agents act as models, simulators and manipulators in the digital learning environment. Moreover, they can add to the believability of simulations with a virtual body and by communicating in a natural manner with learners (Woo, 2008). They can also address a variety of learners' socio-cultural needs in virtual environments by providing opportunities for social interaction (Kim \& Wei, 2011). Agents can also embody personalities by sharing stories about themselves, demonstrating various attitudes, expressing opinions, displaying emotion and empathy and providing encouragement (Gulz, 2005; Woo, 2008). The social presence of pedagogical agents the "persona effect" is expected to increase "learners" interest, attention and motivation (Kramer \& Bente, 2010). The developing relationships between learners and Pas may enhance learners' sense of responsibility, engagement and reduce the loneliness (Gulz, 2005). In comparison to conventional information delivery, virtual agents tend to improve comprehension, retention, recall, problem-solving, self-efficacy, (Dunsworth \& Atkinson, 2007; Murray \& Tenenbaum, 2010), help learners retain information longer (Kim \& Wei, 2011; Woo, 2008; Lusk \& Atkinson, 2007).

However, some research has also shown that simply adding pedagogical agents in e-learning environment does not lead to better learning outcomes, with any benefits being attributed to pedagogy in all the occasions (Clark \& Choi, 2005; Moreno, 2004). Thus, some design refinement with fresh attention to enjoyment, appeal and appearance of pedagogical agents. In a study of "Multiple Intelligent Pedagogical Agents" with multiple roles of PA (Expert, Motivator \& Mentor) for college students Baylor and Kim (2005) found that agent roles were not only perceived by the students to reflect their intended purposes but also led to significant changes in learning and motivation. More specifically, the "Expert" agent led to increased information acquisition the "Motivator" led to increased self-efficacy, and the "Mentor" led to overall improved learning and motivation. The authors have recommended for multi-agent tutoring systems. Some of the popular "Affective Tutorial Agents" are

1) MOODS (de Vicente, 2003)—a simulated ITS tool for diagnosing the level of students' motivation,

2) Auto Tutor (Graesser et al., 2004)—for classifying the students' emotion,

3) Prome Climb (Conati, 2002)—an educational game designed for 11 years. Maths students,

4) Affective Learning Companion (Burleson, 2006)—reflecting on students' non-verbal behaviours,

5) ITSPOKE (Litman \& Riley, 2006) —an ITS that helps student with physics problems and analyses acoustic-prosodic features of student speech and natural language processing,

6) Other (Simonite, 2007)—a Bluetooth-rate, blood pressure and skin conductance data to the tutoring system for analyzing learners' boredom and confusion levels,

7) EMASPEL (Emotional Multi-Agents Systems for peer-to-peer E-learning) (Ben Ammar \& Neji, 2007) where five kinds of agents (i.e. Interface agent, emotional agent, EEC agents, curriculum agent and tutoring agent) have been integrated to promote a more dynamic and flexible affective communication between the learner and affective tutoring system (Neji, Ben Ammar, \& Gouarderes, 2007); ECAs (Embodied Conversational Agents), (Morishima, 2006; Baylor \& Kim, 2005), are anthropomorphic virtual agents that have a human-like look and can interact with the use. Interactions can be of any type ranging from textual input, output, chatting, gestures, speech to even emotion-recognition and generation, which provide and share knowledge with the students as well as encourage and collaborate with them. More recently, Schroeder and Adesope (2013) have advocated for contextually relevant peer pedagogical agent, which can be successfully used by the teachers/instructors in the real classrooms to mobilize and engage the students in deep and active learning. The ET systems like LASP (learner-attenuated system paced) (Mayor \& DaPra, 2012), Xtranamal 
(Miller, 2012), GoAnimate, (Go Animate, 2013), Sitepal (Oddcast Inc., 2013a) and Voki (Oddcast Inc., 2013b) can also be used by instructors for training the teacher educators and act as role models by demonstrating how technology can be effectively used in the classroom (Tondeur et al., 2012).

\subsection{Strengths \& Weaknesses of Affective-Pedagogical Agents}

From the research literature we found the following-

Strengths

1. Affective pedagogical agents have ability to tutor a massive number of people, primarily constrained only by technology resources.

2. Use a conversational style interface;

3. Can boost feelings of self-efficacy;

4. Can tap in a wide source of information (i.e. web databases);

5. Promote individualized instruction, adaptive to user needs;

6. Facilitate people to treat computers like human tutors;

7. Use of 'persona' can boost learner engagement;

8. Remove the barriers in learning;

9. Fantasy element of interacting with another tutor/agent enhances student motivation;

10. Make use of body gestures, facial expressions, voice intonation, the components missing from traditional Computer Based Training (CBT).

Weaknesses

1. There are some "digital divide" issues;

2. Intelligent Affective Pedagogical Agents with multiple functions are very complex to create;

3. Teachers are not typically technology savvy to guide the learners;

4. Natural Language Understanding (NLU) technology is still in its infancy;

5. Text-to-speech uses a robotic voice, often can be annoying to learners;

6. Speech recognition technology is not strong enough for widespread use.

7. People treating the computer as their companion could become over dependent and vulnerable to get its negative effects;

8. Relying on persona can be distracting, if the user does not like the persona's looks, cloths or voice;

9. Can be distracting for younger users;

10. Require massive investment of time, technology resources and money for creating huge database in the domains of knowledge as well as human emotions, expressions, understanding and spontaneous response to learners' emotional needs and organize these into Artificial Intelligence database structure.

\section{Conclusions and Implications}

More recently the Taiwan researchers (Wang et al., 2010; Chen et al., 2012) have designed "Virtual human” tutors and "Empathic Avatar" learning companions, who can use humor and empathy to deal with students' emotions in e-learning context and can encourage and persuade learners to do more learning exercises. By understanding the students' emotional states the virtual human/pedagogical agent can interact with humor and empathy (through clicking emoticons) with learners and the humorous performance can motivate them to learn, interested in learning, handle their emotions better and enhance the performance. Similarly an animator created upper-body performance of the "Avatar" can react with learners in empathic ways, trying to encourage and persuade them into persistent learning. Students can recognize the Avatar's emotions through facial expressions sense of empathic reactions through voice coherence and upper-body behaviours like gestures, head and body movements. All these interactions promote students' performance, learning motivation and engagements. However, the researchers found that students vary with regard to their preferences for the timing and context when the virtual human tutor or Avatar should appear on screen, or how much control they should/want to exercise in learning situation without the interference of agents and the emotions they could handle themselves. The most common emotions found in e-learning situations are boredom frustrations and lack of sustained interest. Often they dislike the agents' persistent persuasion for completing the learning exercises. Thus, a well designed affective pedagogical agent can change the learners' attitude motivation and behaviours towards learning and performance. But the real challenge is to individualize the responses for which the database needs to be much stronger for supporting e-learning systems. Moreover, how the agent can assess the mood of the learner, when 
he wants to explore himself, thus should not interrupt randomly without asking for help. These factors are individual preferences of learners and to what extent affective pedagogical agent can accommodate all these dimensions. In addition to this, different learning activities like reading, writing, solving problems/exercises might affect students' emotions differently. As a result learning activities should be considered an individual case study basis while providing cognitive and affective pedagogical assistance. Thus, we cannot generalize the finding that affective pedagogical agent/Empathic Tutor would invariably motivate all learners and enhance their performance across the culture contents and learning contexts. Moreover, for post secondary learners it may be applicable, but for secondary level Indian student can it be feasible and cost-effective. This raises many more questions about content, pedagogy and software designing. Of course the virtual human tutor can never replace the real-time tutor, but in order to use it as an ICT tool to train and assist our teachers, for spreading mass education and skill training, surely we can venture into this to develop various educational/vocational contents/training modules for addressing fast growing job requirement's and skilled manpower. In Educational Technology research China, Singapore, Taiwan have already made achieved the milestones but for educating the Indian school children we need to update our curriculum, pedagogy as well as educational technology and implement, synchronize these into our school system at the earliest.

\section{References}

Alexander, S. T. V. (2007). An Affect-Sensitive Intelligent Tutoring System with an Animated Pedagogical Agent that Adapts to Student Emotion like a Human Tutor. Doctoral Thesis in Computer Science, Albany, New Zealand: Massey University.

Alexander, S. T. V., Sarrafzadah, A., \& Hill, S. (2006). Easy with Eve: A Functional Affective Tutoring System. Intelligent Tutoring Systems. Jhongli.

Baddeley, A. D. (1992). Working Memory. Science, 255, 556-559. http://dx.doi.org/10.1126/science.1736359

Bandura, A. (1986). Social Foundations of thought and Action: A Social-Cognitive Theory. Englewood Cliffs, NJ: Prentice Hall.

Barrett, L. F., \& Salovey, P. (2002). The Functional Utility of Negative Emotions (p. 467). Handbook of Emotions. Google Books. https://books.google.co.in/books?isbn=1609180445

Baylor, A. L. (1999). Intelligent Agents as Cognitive Tools. Educational Technology, 39, 36-40.

Baylor, A., \& Kim, Y. (2005). Simulating Instructional Roles through Pedagogical Agents. International Journal of Artificial Intelligence in Education, 15, 95-115.

Bechara, A., Damasio, H., \& Damasio, A. R. (2003). Role of the Amygdala in Decision-Making. Annals of the New York Academy of Sciences, 985, 356-369. http://dx.doi.org/10.1111/j.1749-6632.2003.tb07094.x

Ben Ammar, M., \& Neji, M. (2007). EMASPEL (Emotional Multi-Agents System for Peer-to-Peer E-Learning). The 1st International Conference on Information and Communication Technology and Accessibility. Hammamet, Tunisia, April 12-14.

Burleson, W. (2006). Affective Learning Companions: Strategies for Empathetic Agents with Real-Time Multimodal Affective Sensing to Foster Meta-Cognitive and Meta-Affective Approaches to Learning, Motivation, and Perseverance. Ph.D. Thesis, Cambridge, MA: Massachusetts Institute of Technology.

Chen, G.-D., Lee, J.-H., Wang, C.-H., Chao, P.-Y., Li, L.-Y., \& Lee, T.-Y. (2012). An Empathic Avatar in a Computer-Aided Learning Program to Encourage and Persuade Learners. Educational Technology \& Society, 15, 62-72.

Chou, C., Chan, T., \& Lin, C. (2003). Redefining the Learning Companion: The Past, Present, and Future of Educational Agents. Computers in Education, 40, 255-269. http://dx.doi.org/10.1016/S0360-1315(02)00130-6

Clarebout, G., \& Elen, J. (2007). In Search of Pedagogical Agents’ Modality and Dialogue Effects in Open Learning Environments. Journal of Instructional Science and Technology, 10, 1-15.

Clark, R. E., \& Choi, S. (2005). Five Design Principles for Experiments on the Effects of Animated Pedagogical Agents. Journal of Educational Computing Research, 32, 209-225. http://dx.doi.org/10.2190/7LRM-3BR2-44GW-9QQY

Conati, C. (2002). Probabilistic Assessment of User's Emotions in Educational Games. Journal of Applied Artificial Intelligence, 16, 555-575. http://dx.doi.org/10.1080/08839510290030390

D’Mello, S., Picard, R., \& Graesser, A. (2007). Toward an Affect-Sensitive Auto Tutor. IEEE Intelligent Systems, 22, 53-61. http://dx.doi.org/10.1109/MIS.2007.79

Damasio, A. R., Grabowski, T. J., Bechara, A., Domasio, H., Panto, L. L. B., Parizi, J., \& Hichwa, R. D. (2000). Sub-Cortical and Cortical Brain Activity during the Feeling of Self-Generated Emotions. Nature Neuroscience, 3, 1049-1056.

http://dx.doi.org/10.1038/79871 
De Vicente, A. (2003). Towards Tutoring Systems That Detect Students’ Motivation: An Investigation. PhD Thesis, Edinburgh: School of Informatics, University of Edinburgh.

Dunsworth, Q., \& Atkinson, R. (2007). Fostering Multimedia Learning of Science: Exploring the Role of an Animated Agent's Image. Computers in Education, 49, 677-690. http://dx.doi.org/10.1016/j.compedu.2005.11.010

Fox, B. (1991). Cognitive and Interactional Aspects of Correction in Tutoring. In P. Goodyear (Ed.), Teaching Knowledge and Intelligent Tutoring. Norwood, NJ: Ablex.

Gardner, H. (1999). Intelligence Reframed: Multiple Intelligences for the 21st Century (292 p). New York: Basic Books.

Go Animate (2013). Go Animate (Computer Software). http://goanimate.com

Graesser, A. C., Lu, S., Jackson, G. T., Mitchell, H., Ventura, M., Olney, A., \& Louwerse, M. M. (2004). Auto Tutor: A Tutor with Dialogue in Natural Language. Behavioral Research Methods, Instruments, and Computers, 36, 180-193. http://dx.doi.org/10.3758/BF03195563

Graesser, A., Jeon, M., \& Dufty, D. (2008). Agent Technologies Designed to Facilitate Interactive Knowledge Construction. Discourse Processes, 45, 298-322. http://dx.doi.org/10.1080/01638530802145395

Gulz, A. (2004). Benefits of Virtual Characters in Computer Based Environments: Claims and Evidence. International Journal of Artificial Intelligence in Education, 14, 313-334.

Gulz, A. (2005). Social Enrichment by Virtual Characters: Differential Benefits. Journal of Computer Assisted Learning, 21, 405-418. http://dx.doi.org/10.1111/j.1365-2729.2005.00147.x

https://books.google.co.in/books/about/Intelligence_Reframed.html2id=n0HsjJBO\&c

Isen, A. M. (1999a). Positive Affect. In T. Dalgleish, \& M. Power (Eds.), The Handbook of Cognition and Emotion (pp. 521-539). Sussex: Wiley.

Isen, A. M. (1999b). Positive Affect and Creativity. In S. Russ (Ed.), Affect, Creative Experience, and Psychological Adjustment (pp. 3-17). Philadelphia, PA: Bruner/Mazel.

Isen, A. M. (2000). Some Perspective on Positive Affect and Self-Regulation. Psychological Inquiry, 11, 184-187.

Isen, A. M., \& Reeve, J. (2005). The Influence of Positive Affect on Intrinsic and Extrinsic Motivation: Facilitating Enjoyment of Play Responsible Work Behavior, and Self-Control. Motivation and Emotion, 29, 295-323.

http://dx.doi.org/10.1007/s11031-006-9019-8

Kim, C., \& Baylor, A. (2008). A Virtual Change Agent: Motivating Pre-Service Teachers to Integrate Technology in Their Future Classrooms. Educational Technology \& Society, 11, 309-321.

Kim, Y., \& Baylor, A. (2006). A Socio-Cognitive Framework for Pedagogical Agents as Learning Companions. Educational Technology, Research and Development, 54, 569-596. http://dx.doi.org/10.1007/s11423-006-0637-3

Kim, Y., \& Wei, Q. (2011). The Impact of Learner Attributes and Learner Choice in an Agent-Based Environment. Computer in Education, 56, 505-514. http://dx.doi.org/10.1016/j.compedu.2010.09.016

Kim, Y., Baylor, A. L., \& Shen, E. (2007). Pedagogical Agents as Learning Companions: The Impact of Agent Emotion and Gender. Journal of Computer Assisted Learning, 23, 220-234. http://dx.doi.org/10.1111/j.1365-2729.2006.00210.x

Kinard, T. A. (2001). The Potential of Affective Computing in E-Learning. In Chapter 14: The Journey from Theory to Practice in the "Myself" Project. www.irma-international.org/viewtitle/40562

Kort, B., Riley, R., \& Picard, R. W. (2001). An Affective Model of Interplay between Emotions and Learning: Reengineering Educational Pedagogy Building a Learning Companion. Proceedings of IEEE International Conference on Advanced Learning Technologies, Madison, 6-8 August 2001, 0043. http://dx.doi.org/10.1109/ICALT.2001.943850

Kramer, N. C., \& Bente, G. (2010). Personalizing E-Learning: The Social Effects of Pedagogical Agents. Educational Psychology Review, 22, 71-87. http://dx.doi.org/10.1007/s10648-010-9123-x

Lane, L. A., Ayres, J. F., \& Lovett, J. V. (1997). A Review of the Introduction and Use of White Clover (Trifolium repens L.) in Australia-Significance for Breeding Objectives. Australian Journal of Experimental Agriculture, 37, 831-839 http://dx.doi.org/10.1071/EA97044

Lepper, M. R., Aspinwall, L., Mumme, D., \& Chabay, R. W. (1990). Self-Perception and Social Perception Processes in Tutoring: Subtle Social Control Strategies of Expert Tutors. In J. M. Olsen, \& M. P. Zanna (Eds.), Self-Inference and Social Inference: The Ontario Symposium. Hillsdale, NJ: Erlbaum.

Lisetti, C. (1999). Modeling Cognition-Emotion of Users for Improved Interaction with Software Systems. In J. Kay (Ed.), UM99 User Modeling (pp. 307-309). Vienna: Springer. http://dx.doi.org/10.1007/978-3-7091-2490-1 33

Litman, D. J., \& Riley, F. K. (2006). Recognizing Student Emotions and Attitudes on the Basis of Utterances in Spoken Tutoring Dialogues with Both Human and Computer Tutors. Speech Communication, 48, 559-590.

http://dx.doi.org/10.1016/j.specom.2005.09.008 
Mantovani, F. et al. (2010). Cognitive Constructor: An Intelligent Tutoring System Based on a Biologically Inspired Cognitive Architecture (BICA). In Conversational Agents and Natural Language Interaction: Techniques and Effective Practices. https://books.google.co.in/book?isbn=1609606183

Mayor, R. E., \& DaPra, C. S. (2012). An Embodiment Effect in Computer-Based Learning with Animated Pedagogical Agents. Journal of Experimental Psychology: Applied, 18, 239-252. http://dx.doi.org/10.1037/a0028616

Merrill, D. C., Reiser, B. J., Ranney, M., \& Trafton, J. G. (1992). Effective Tutoring Techniques: A Comparison of Human Tutors and Intelligent Tutoring Systems. Learning Sciences, 2, 277-300. http://dx.doi.org/10.1207/s15327809jls0203_2

Miller, R. H. (2012) Online Ethics Course Aims at Tough Issues. http://news.wsu.edu/pages/publications.asp?Action=Detail\&PublicationID=32496\&pageID $=$ on

Moreno, R. (2004). Animated Pedagogical Agents in Educational Technology. Educational Technology, 44, $23-30$.

Morishima, A. (2006). Digital Libraries: Achievement, Challenges, and Opportunities. 9th International Conference on Asian Digital Libraries (ICADL), Kyoto, 27-30 November 2006.

Mota, S., \& Picard, R. W. (2003). Automated Posture Analysis for Detecting Learner's Interest Level. Conference on Computer Vision and Pattern Recognition Workshop, 5, 49. http://dx.doi.org/10.1109/cvprw.2003.10047

Murray, M., \& Tenenbaum, G. (2010). Computerized Pedagogical Agents as an Educational Means for Developing Physical Self-Efficacy and Encouraging Activity in Youth. Journal of Educational Computing Research, 42, 267-283. http://dx.doi.org/10.2190/EC.42.3.b

Neji, M., Ben Ammar, M., \& Gouarderes, G. (2007). Affective Communication for Peer-to-Peer E-Learning. International Conference on Computing and E-Systems, Hammamet, 12-14 March 2007, 252-268.

Oddcast Inc. (2013a). SitePal (Computer Software). http://sitepal.com/

Oddcast Inc. (2013b). Voki (Computer Software). http://www.voki.com/

Payr, S. (2003). The Virtual University’s Faculty: An Overview of Educational Agents. Applied Artificial Intelligence, 17, 1-19. http://dx.doi.org/10.1080/713827053

Pekrun, R., Goetz, T., Titz, W., \& Perry, R. P. (2002). Academic Emotions in Students' Self-Regulated Learning and Achievement: A Program of Quantitative and Qualitative Research. Educational Psychologist, 37, 91-106. http://dx.doi.org/10.1207/S15326985EP3702 4

Picard, R. W. (1997). Affective Computing. Cambridge, MA: MIT Press.

Picard, R. W. (1998). Towards Agents That Recognize Emotion. In IMAGINA, Monaco.

Picard, R., \& Burleson, W. (2004). Affective Agents: Sustaining Motivation to Learn through Failure and a State of "Stuck". The 7th Conference on Intelligent Tutoring Systems: Workshop on Social and Emotional Intelligence in Learning Environments, Maceio, Brasil.

Picard, R., Reilly, R., \& Kart, B. (2004). An Affective Model of Interplay between Emotions and Learning. In P. Exman, R. Levenson, \& W. Friesen (Eds.), Autonomic Nervous System Activity Distinguishes among Emotions, Science, 221, Citeseer.

Prendinger, H., \& Ishizuka, M. (2007). Symmetric Multi-Modality Revisited: Unveiling User’s Physiological Activity. Industrial Electronics, 54, 692-698. http://dx.doi.org/10.1109/TIE.2007.891646

Prendinger, H., \& Ishizuka, M. (Eds.) (2004). Life-Like Characters: Tools, Affective Functions, and Applications. Heidelberg: Springer Verlag. http://dx.doi.org/10.1007/978-3-662-08373-4

Prendinger, H., Mori, J., \& Ishikreza, M. (2005). Using Human Physiology to Evaluate Subtle Expressivity of a Virtual Quizmaster in a Mathematical Game. International Journal of Human-Computer Studies, 62, 231-245.

http://dx.doi.org/10.1016/j.ijhcs.2004.11.009

Reeves, B., \& Nass, C. (1996). The Media Equation: How People Treat Computers, Television and New Media Like Real People and Places. New York: Cambridge University Press.

Rosenberg-Kima, R., Baylor, A., Plant, E., \& Doerr, C. (2008). Interface Agents as Social Models for Female Students: The Effects of Agent Visual Presence and Appearance on Female Students' Attitudes and Beliefs. Computers in Human Behaviour, 24, 2741-2756. http://dx.doi.org/10.1016/j.chb.2008.03.017

Sarrafzadeh, A. F., Dadgostar, F., Alexander, S., \& Messom, C. (2004). Frown Gives Game Away: Affect Sensitive Tutoring Systems for Elementary Mathematics. IEEE International Conference on Systems, Man and Cybernetics, 1, 13-18.

Schroeder, N. L., \& Adesope, O. O. (2013). How Does a Contextually-Relevant Peer Pedagogical Agent in a Learner-Attenuated System-Paced Learning Environment Affect Cognitive and Affective Outcomes? Journal of Teaching and Learning with Technology, 2, 114-133.

Schutz, P. A., \& Pekrun, R. (2007). Introduction to Emotion in Education. In P. A. Schutz, \& R. Pekrun (Eds.), Emotion in Education: A Volume in Educational Psychology (pp. 3-10). Cambridge, MA: Academic Press, Elsevier Inc. 
Simonite, T. (2007). Emotion Aware Teaching Software Tracks Student Attention. http://www.newsscientisttech.com/article.ns?id=dn10894\&feedId=online-news_rss20

Sklar, E., \& Richards, D. (2010). Agent-Based Systems for Human Learners. The Knowledge Engineering Review, 25, 111135. http://dx.doi.org/10.1017/S0269888910000044

Sweller, J. (1994). Cognitive Load Theory, Learning Difficulty and Instructional Design. Learning and Instruction, 4, 295312. http://dx.doi.org/10.1016/0959-4752(94)90003-5

Sweller, J. (2004). Instructional Design Consequences of an Analogy between Evolution by Natural Selection and Human Cognitive Architecture. Instructional Science, 32, 9-31. http://dx.doi.org/10.1023/B:TRUC.0000021808.72598.4d

Tondeur, J., Van Braak, J., Sang, G., Voogt, J., Fisser, P., \& Qttenbreit-Leftwich, A. (2012). Preparing Pre-Service Teachers to Integrate Technology in Education: A Synthesis of Qualitative Evidence. Computers and Education, 59, 134-144.

Veletsianos, G. (2010). Contextually Relevant Pedagogical Agents: Visual Appearance, Stereotypes, and First Impressing and Their Impact on Learning. Computers in Education, 55, 576-585. http://dx.doi.org/10.1016/j.compedu.2010.02.019

Veletsianos, G., \& Russell, G. S. (2013). Pedagogical Agents. In J. M. Spector et al. (Eds.), Handbook of Research on Educational Communications and Technology. New York: Springer Science + Business Media.

Wang, C.-Y., Ke, S.-Y., Chuang, H.-C., Tseng, H.-Y., \& Chen, G.-D. (2010). E-Learning System Design with Humor and Empathy Interaction by Virtual Human to Improve Students' Learning. Proceedings of the 18th International Conference on Computers in Education, Putrajaya.

Woo, H. L. (2008).Designing Multimedia Learning Environments Using Animated Pedagogical Agents: Factors and Issues. Journal of Computer Assisted Learning, 25, 203-218. 